\title{
Diversity and Pathogenicity of Rhizoctonia Species from the Brazilian Cerrado
}

Angel José Vieira Blanco and Marília Oliveira Costa, Goiás Federal Institute of Education, Science and Technology - Campus Inhumas, Inhumas, GO, Brazil 75400-000; Roberto do Nascimento Silva, Department of Biochemistry and Immunology, Ribeirão Preto Medical School, University of São Paulo, SP, Brazil 14049-900; Fábio Suzart de Albuquerque, Science and Mathematics Faculty, College of Integrative Sciences and Arts, Arizona State University; Arthur Tavares de Oliveira Melo, Department of Biological Sciences, College of Life Sciences and Agriculture, University of New Hampshire, Durham, NH 03824; Fabyano Alvares Cardoso Lopes, Institute of Biology, Federal University of Rio de Janeiro, Rio de Janeiro, RJ, Brazil 21941-599; Andrei Stecca Steindorff, Department of Cell Biology, Biological Sciences Institute, Brasília University Campus Darcy Ribeiro, Brasília, DF, Brazil, 70910-900; Elder Tadeu Barbosa, Brazilian Agricultural Research Corporation, Embrapa Arroz e Feijão, Santo Antônio de Goiás, GO, Brazil, 75375-000; Cirano José Ulhoa, ${ }^{\dagger}$ Biological Sciences Institute, Biochemistry and Molecular Biology Department, Goiás Federal University, Campus Samambaia, Goiânia, GO, Brazil, 74690900; and Murillo Lobo Junior, Brazilian Agricultural Research Corporation, Embrapa Arroz e Feijão, Santo Antônio de Goiás, GO, Brazil, $75375-000$

\begin{abstract}
Eighty-one Rhizoctonia-like isolates were identified based on morphology and nuclei-staining methods from natural and agricultural soils of the Cerrado (Brazilian savanna). The nucleotide similarity analysis of ITS1-5.8S-ITS2 regions identified 14 different taxa, with $39.5 \%$ of isolates assigned to Waitea circinata (zeae, oryzae, and circinata varieties), while $37.0 \%$ belonged to Thanatephorus cucumeris anastomosis groups (AGs) AG1-IB, AG1-ID, AG1-IE, AG4-HGI, and AG4-HGIII. Ceratobasidium spp. AG-A, AG-F, AG-Fa, AG-P, and AG-R comprised $23.5 \%$. Rhizoctonia zeae (19.8\%), R. solani AG1-IE (18.6\%), and binucleate Rhizoctonia AG-A $(8.6 \%)$ were the most frequent anamorphic states

found. Root rot severity caused by the different taxa varied from low to high on common beans, and tended to be low to average in maize. Twenty-two isolates were pathogenic to both hosts, suggesting difficulties in managing Rhizoctonia root rots with crop rotation. These results suggest that cropping history affects the geographical arrangement of AGs, with a prevalence of AG1 in the tropical zone from central to north Brazil while the AG4 group was most prevalent from central to subtropical south. W. circinata var. zeae was predominant in soils under maize production. To our knowledge, this is the first report on the occurrence of W. circinata var. circinata in Brazil.
\end{abstract}

Rhizoctonia is an important genus of phytopathogenic fungi associated with various plant tissues. They are cosmopolitan organisms found in soils under agricultural cultivation and in native vegetation (González-García et al. 2006), and survive saprophytically or remain dormant as sclerotia (Bruehl 1987). Rhizoctonia species are highly diversified, with the sexual teleomorphic and asexual anamorphic stages causing important plant diseases (Sneh et al. 1991).

There are three main teleomorphic stages of Rhizoctonia associated with plant diseases: Thanatephorus cucumeris, a multinucleated species $($ anamorph $=$ Rhizoctonia solani); Ceratobasidium spp., a binucleate species often classified as Ceratorhiza (anamorphic state); and Waitea circinata, a multinucleated species with five known varieties: zeae, oryzae, circinata, prodigus, and agrostis (Kammerer et al. 2011; Leiner and Carling 1994).

T. cucumeris is regarded as the most important plant pathogen within this group, causing diseases in over 200 hosts, including major grain crops (such as rice, common bean, maize, wheat, and soybean), vegetables, fruits, trees, weeds, and ornamentals (González et al. 2006). This species causes either root or foliar diseases and, according to hyphal fusion between compatible isolates, is divided into 13 anastomosis groups (AG1 to AG13). Some AGs may be subdivided into intraspecific groups (ISGs), based on phenotypic traits like colony morphology, nutritional requirements, growth temperature, host range, and pathogenicity (Carling et al. 2002).

${ }^{\dagger}$ Corresponding author: C. J. Ulhoa; E-mail: ulhoa@ufg.br

The authors are grateful to the Brazilian National Council for Scientific and Technological Development (CNPq) that supported this study with research grant 578604/2008-6.

Accepted for publication 23 October 2017.

C 2018 The American Phytopathological Society
The teleomorphic genus Ceratobasidium is quite diverse, and includes pathogens, saprophytes, and mycorrhizae (Ogoshi 1987). Ceratobasidium spp. infect common bean, potato, sugarbeet, rice, pea, rye, and oats (González et al. 2001; Sneh et al. 1991, 1996). There are also reports of sheath blight, normally attributed to T. $\mathrm{cucu}$ meris (Li et al. 1998), and web blight (Nechet and Halfeld-Vieira 2006). The taxonomy of Ceratobasidium is also based on hyphal anastomosis and is currently organized in 16 AGs, as discussed by Sharon et al. (2008).

The five varieties oryzae, zeae, circinata, agrostis, and prodigus of $W$. circinata were established with the support of genetic dissimilarity analysis (de la Cerda et al. 2007; Sharon et al. 2006; Toda et al. 2007). The epithet "Rhizoctonia" has not been adopted yet for the agrostis and prodigus varieties, and only the varieties oryzae and zeae have been linked to the anamorphic genus. Zeae is the most common $W$. circinata variety due to its host range, which includes commonly grown crops such as maize, rice, onions, canola, wheat, and barley (Sneh et al. 1991, 1996).

The identification of Rhizoctonia species and their ISGs is a requirement for disease management in agricultural areas. The large number of hosts, their saprophytic capacity, the absence of resistant plant cultivars, and the limitations on chemical control makes disease management through genetic resistance and cultural practices a challenge for growers and the rural extension service (Amaradasa et al. 2014; Costa-Coelho et al. 2014, 2016). Without efficient management, the level of inoculum in soil increases and can lead to significant yield losses.

The identification of Rhizoctonia spp. still considers morphological, nuclei-staining, and cultural aspects, but relies mostly on geneticbased methods to confirm the identity of species, varieties, and their AGs. Of these molecular-based methods, genetic nucleotide analysis of the intergenic ITS region of ribosomal DNA (rDNA) is considered an important tool for Rhizoctonia species classification (Sharon et al. 2006, 2008; White et al. 1990).

The majority of studies on the morphology and genetic diversity of Rhizoctonia species in Brazil are usually specific for a single crop or a specific AG (Ceresini 2014; Ciampi et al. 2009; Gaino et al. 2010). This 
narrow focus is due to a lack of information about the geographic distribution and genetic diversity of Rhizoctonia species across the Brazil.

Hypothetically, cultural practices and environmental factors can affect the distribution of Rhizoctonia species and AGs (Fenille et al. 2002; Hua et al. 2014). Thus, it is important to link species distribution to mechanisms responsible for the spread and establishment of these pathogens in relevant agricultural regions. This is especially important in the Cerrado (Brazilian savanna), where intensive agriculture, including growing two to three crops per year, facilitates the establishment of soilborne pathogens.

The objectives of this study were to: i) identify species and ISGs of Rhizoctonia spp. recovered from soils under native vegetation and agricultural production the Brazilian Cerrado, and ii) verify the pathogenicity of isolates on maize and common beans roots.

\section{Materials and Methods}

Sampling sites and strain isolation. All isolates were obtained from soil samples in different agricultural and native vegetation areas from in the Brazilian Cerrado. The samples were distributed throughout the eight Brazilian states: Bahia (BA), Goiás (GO), Minas Gerais (MG), Mato Grosso (MT), Paraná (PR), Roraima (RR), São Paulo (SP), and Tocantins (TO) (Fig. 1). Seventy samples were from agricultural areas with 37 under monoculture, 17 from crop rotation systems, and 16 from soils without a known cropping history. The remaining 11 samples were from areas of native vegetation. All samples were collected from the top $10 \mathrm{~cm}$ of soil using either the
Weinhold (1977) method or the Paulitz and Schroeder (2005) protocol and stored in sterilized paper stripes at $-20^{\circ} \mathrm{C}$ or $-80^{\circ} \mathrm{C}$. A working collection of 81 isolates with morphological traits typical of Rhizoctonia species was stored from the Fungal and Functional Microorganisms Culture Collection from the Brazilian Agricultural Research Corporation (EMBRAPA), at Embrapa Arroz e Feijão research center, Santo Antônio de Goiás. The specimens were removed from refrigeration for study and grow on $2 \%$ water agar with chloramphenicol (200 ppm) at $25^{\circ} \mathrm{C}$ for 5 days.

Nuclei staining and colony morphology. We evaluated the isolates for typical Rhizoctonia-like morphological traits, such as $90^{\circ}$ mycelial branching of the hyphae, absence of conidia, lack of clamp connections, number of nuclei per cell, color of the mycelium, and presence of sclerotia in the culture medium (Sneh et al. 1991, 1996). For morphological analysis, a 5-mm-diameter mycelial disc was transferred to a glass slide for examination at $1,000 \times$ optical microscopy. Fungal nuclei were stained with Safranin-O (Bandoni 1979) and the number of nuclei in each of 10 cells per glass slide was recorded. The procedure was repeated until 100 cells per slide were examined.

Genomic DNA extraction and sequencing of ribosomal DNA. The genomic DNA (gDNA) of each isolate was extracted according to Lopes et al. (2012) and checked for quality with spectrophotometry at 260 and $280 \mathrm{~nm}$. The ITS1-5.8S-ITS2 region was amplified using primers ITS1 and ITS4 (White et al. 1990). The PCR products were purified and sequenced using the DYEnamicTM ET Terminator

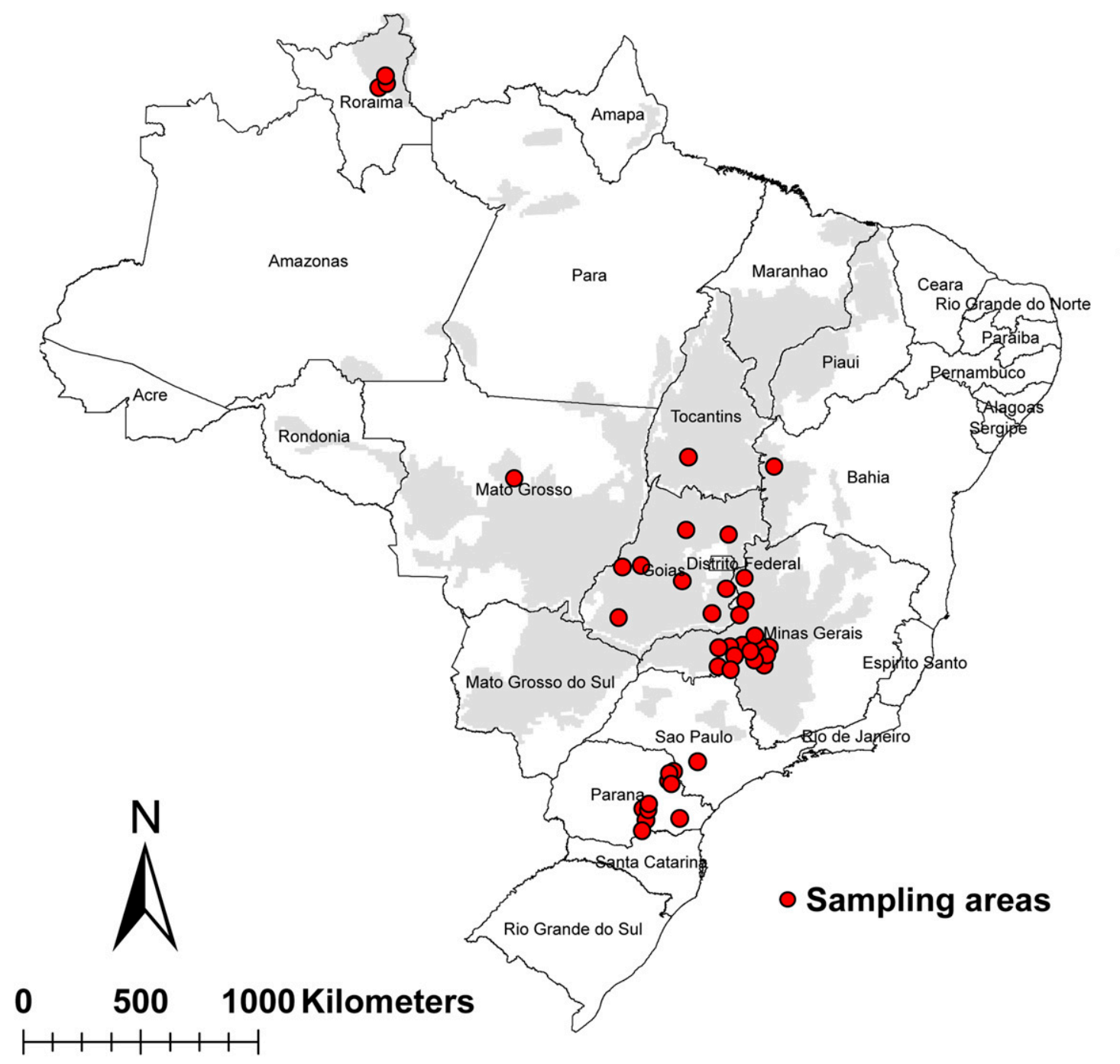

Fig. 1. Spatial distribution of the sampling sites from which 81 isolates of Rhizoctonia species were collected. These sampling sites (gray area) cover the five main Brazilian regions of the Cerrado (Brazilian Savanna) biome. 
Cycle Sequencing kit (GE Healthcare, U.S.A.) in an ABI Prism 3100 (Applied Biosystems).

Species, varieties, and AG identification and phylogenetic analysis. To identify the 81 Rhizoctonia-like isolates, a nucleotide similarity analysis through the BLASTn v.2.2.30 algorithm was performed using the rDNA sequences as query sequences and the nonredundant nucleotide database of NCBI as a reference. The best-hit sequences with the lower e-value that maximized the coverage of query sequences were chosen and used to classify the samples at species, variety, and AG levels. Eventually, to avoid misidentification due to partially characterized sequences in GenBank, we used the next best-hits and morphological traits (Sneh et al. 1991, 1996) to support our classifications.

Subsequently, the nucleotide rDNA sequences were aligned using Clustal X v.2.1 software and manually edited with Bioedit v.7.1.7 software (Hall 1999). To determine the phylogenetic relationships among the Brazilian Cerrado isolates, nucleotide sequences of the ITS-rDNA region of Rhizoctonia spp. in GenBank were used as references (Table 1).

All rDNA nucleotide sequences investigated in this study were deposited in GenBank, with accession numbers KM065536, KM065539_ KM065541, KM065544-KM065546, KM065548-KM065557, KM065559-KM065570, KX468789, KX468791, and KX468793KX468842. These and 15 sequences from Johanson et al. (1998); Mora-Umaña et al. (2013); Sharon et al. (2007, 2008); Toda et al. (2004, 2007), and AG-R and outgroup (V. Gonzales; Xie et al., unpublished data) were assembled in a phylogenetic tree constructed with MEGA software v.6.06 (Tamura et al. 2013) based on maximum parsimony (MP), with 1,000 bootstraps. Therefore, the data set used in the phylogenetic analysis resulted in a total of 96 sequences: 81 Brazilian Cerrado isolates and 15 reference sequences from GenBank.

Pathogenicity tests and disease severity assessments. Pathogenicity tests on common beans (Phaseolus vulgaris L. var. Pérola) and maize (Zea mays L., MCP10 genotype) were conducted using the single-inoculum layer method (Chaudhary et al. 2006). In separate tests for each crop species, 10 disinfested seeds were planted in two $500-\mathrm{ml}$ polyethylene containers $(9 \mathrm{~cm}$ diameter $\times 12 \mathrm{~cm}$ height), five seeds each, filled with vermiculite and a 5-day-old colony of the test isolate on potato dextrose agar (PDA). The containers were incubated in a growth chamber at $20 \pm 1^{\circ} \mathrm{C}$ for 21 days with a $12-\mathrm{h}$ photoperiod and watered three times a week. The experiments were carried out under a completely randomized design testing isolate pathogenicity in 10 individual plants, each one considered an experimental unit, with noninoculated containers as control plots.

After harvest, plant roots were washed in tap water and checked for disease severity using a 1 to 9 scale (Schoonhoven and Pastor-Corrales 1987), where 1 = no visible symptoms; 3 = from light discoloration

Table 1. Reference sequences used in the analysis of phylogenetic relationships between Rhizoctonia spp. from the Brazilian Cerrado

\begin{tabular}{lll}
\hline $\begin{array}{l}\text { GenBank } \\
\text { accession no. }\end{array}$ & \multicolumn{1}{c}{ Rhizoctonia spp. } & \multicolumn{1}{c}{ Reference } \\
\hline AB213594 & Waitea circinata var. zeae & Toda et al. (2007) \\
AB213584 & W. circinata var. circinata & Toda et al. (2007) \\
AJ000195 & W. circinata var. oryzae & Johanson et al. (1998) \\
AB122140 & Thanatephorus cucumeris & Toda et al. (2004) \\
& AG1-IB & \\
AB122125 & T. cucumeris AG1-ID & Toda et al. (2004) \\
JX294338 & T. cucumeris AG1-IE & Mora-Umaña et al. (2013) \\
AY387543 & T. cucumeris AG4- HGI & Sharon et al. (2008) \\
DQ102449 & T. cucumeris AG4- HGIII & Sharon et al. (2007) \\
DQ102421 & Ceratobasidium AG-A & Sharon et al. (2007) \\
AB219144 & Ceratobasidium AG-Fa & Sharon et al. (2007) \\
AB219145 & Ceratobasidium AG-Fb & Sharon et al. (2007) \\
DQ102401 & Ceratobasidium AG-G & Sharon et al. (2007) \\
AB286941 & Ceratobasidium AG-P & Sharon et al. (2008) \\
AJ427407 & Ceratobasidium AG-R & (Unpublished work) \\
JF819727 & Athelia rolfsii (outgroup) & (Unpublished work) \\
\hline
\end{tabular}

and no necrotic lesions to a maximum of $10 \%$ of hypocotyl and root tissues with lesions; 5 = approximately $25 \%$ of hypocotyl and root tissues have lesions, but the tissues remain firm; $7=$ approximately $50 \%$ of hypocotyl and root tissues have lesions, root systems with considerable decay and reductions; and $9=$ approximately $75 \%$ or more of the hypocotyl and root tissues have lesions, and roots with advanced stages of decay and considerable reduction. Isolates were compared for disease severity with the Kruskal-Wallis (KW) nonparametric test at 5\% significance, regarding severity among the different genera (intergenera test), and in intragenera tests regarding the different species, variety, and AGs. Statistical procedures were performed with Statistica software (StatSoft, Inc. 2007) and R (R Core Team 2015).

\section{Results}

Species, varieties, and AG identification. All 81 isolates collected across the Brazilian Cerrado were successfully classified as species of Rhizoctonia, in 14 different taxa. While $39.5 \%$ of the isolates were assigned to $W$. circinata varieties zeae, oryzae, and circinata, $37.0 \%$ belonged to T. cucumeris (AG1-IB, AG1-ID, AG1-IE, AG4-HGI, and AG4-HGIII), and $23.5 \%$ were characterized as Ceratobasidium (AG-A, AG-F, AG-Fa, AG-G, AG-P, and AG-R). According to molecular identification, the percentage of sequence similarities ranged from 78 to $100 \%$.

All $W$. circinata isolates were multinucleated with mycelial color ranging from orange to salmon or light brown (Fig. $2 \mathrm{~L}-\mathrm{N}$ ). $W$. circinata var. zeae and W. circinata var. circinata isolates formed

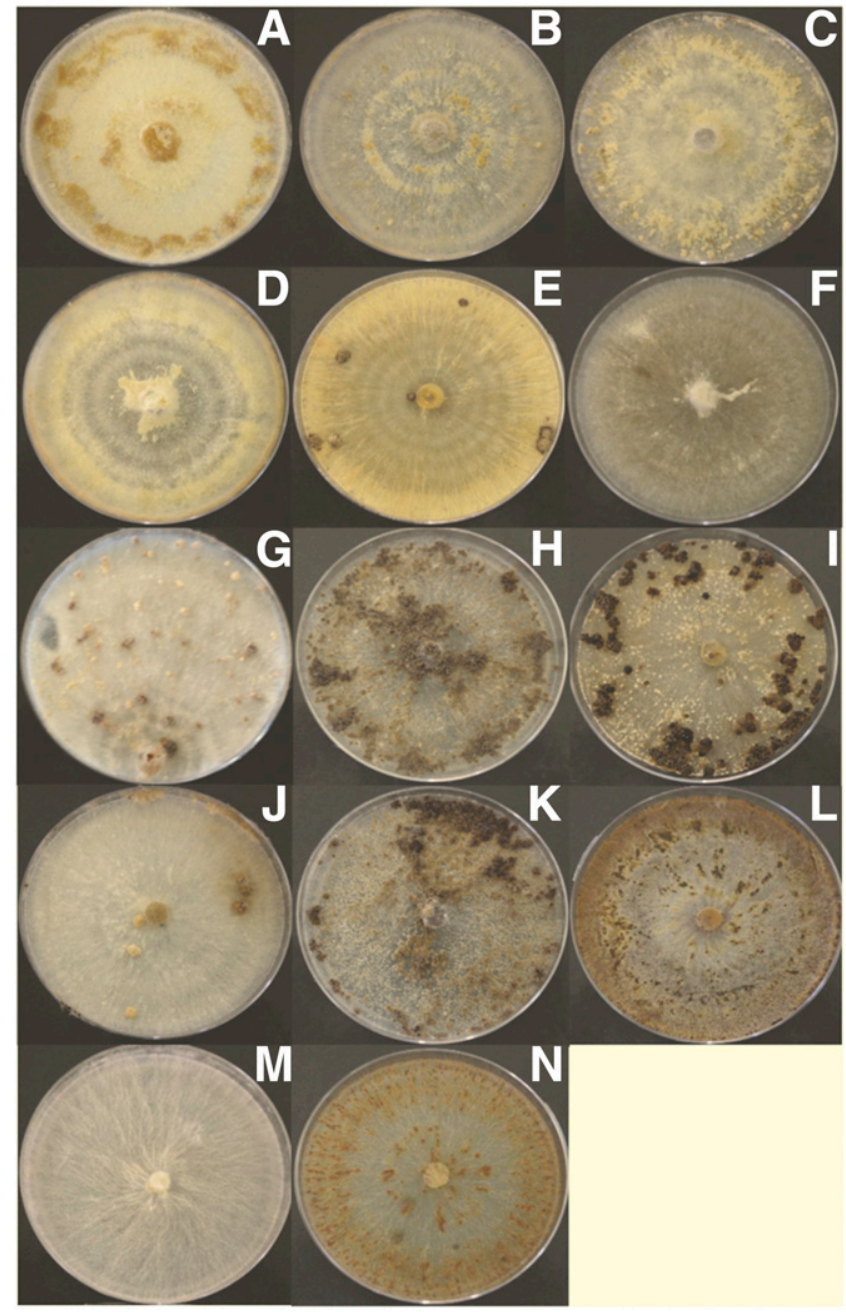

Fig. 2. Colony morphology of isolates of Rhizoctonia species collected from the Brazilian Cerrado. A-F, Ceratobasidium spp. (AGA, AGF, AGFA, AGG, AGP, and AGR); G-K, Thanatephorus cucumeris (AG1-IB, AG1-ID, AG1-IE, AG4-HGII, and AG4HGIII). L-N, Waitea circinata (var. circinata, var. oryzae, and var. zeae), respectively. 
sclerotia after 40 days of growth, in contrast to W. circinata var. ory$z a e$, which did not form sclerotia. Zeae and circinata were the main W. circinata varieties representing, respectively, 19.8 and $18.5 \%$ of the total (Table 2). According to the geographical distribution and the relative and absolute frequencies of the isolates, $W$. circinata was the most common species in the states of Goiás, Minas Gerais, and Paraná.

T. cucumeris accounted for $37 \%$ of the total and were all multinucleated, with mycelium color ranging from light brown to dark brown (Fig. 2G-K). The only two T. cucumeris AGs identified were AG1 and AG4. Isolates belonging to AG1 were in three ISGs (IB, ID, and IE), while AG4 isolates were from the HGI and HGIII subgroups. All T. cucumeris AG4 isolates were obtained from agricultural areas located in the states of Paraná, São Paulo, Minas Gerais, and Goiás, while the AG1 isolates were found in both agricultural soils or under native vegetation located in Roraima and Mato Grosso (Table 3).

Isolates classified as AG1 and AG4 formed sclerotia, whose dimensions, amounts, and staining apparently varied according to the ISG. The T. cucumeris isolates classified as AG1-1E (14.8\%) and AG4-HGI (9.9\%) were the most frequent. The isolates labeled as AG1-1B, AG1-ID, and AG4-HGIII corresponded respectively to $3.7,2.5$, and $6.2 \%$ of the relative frequency within this group.

Almost all isolates classified as Ceratobasidium had two nuclei per cell, except for isolates CNPAF_0036, CNPAF_0255, and CNPAF_0258, which were multinucleate (Table 4). Isolates had a yellowish-white mycelium, powdery texture, and a variable number of light-colored sclerotia (Fig. 2A-F). This genus also had the lowest number of isolates (23\%), with AG-A and AG-F accounting for 8.6 and $6.2 \%$, respectively. The other Ceratobasidium AGs were AG-Fa, AG-P, AG-G, and AG-R, and together resulted in less than $10 \%$ of isolates. The AG-A group had a higher frequency in soils under common bean cultivation, along with AG-F and AG-Fa. Furthermore,
Ceratobasidium AG-G and AG-R were isolated mainly from soils under carrot and onion cultivation, respectively.

Pathogenicity and disease severity tests on common bean and maize. The pathogenicity tests showed that all isolates were pathogenic on at least one host, common bean or maize, but had different levels of disease severity. On common bean, $53.1 \%$ of the isolates were pathogenic and $45.7 \%$ infected maize. Twenty-two isolates $(27.1 \%)$ caused root rot symptoms on both hosts. Isolates CNPAF 0076, 0119, 0144, 0152, 0180, 0189, 0193, 0215, 0238, 0240, 0246, 0248 (T. cucumeris), 0088, 0093, 0117, 0129, 0255, 0258 (Ceratobasidium), 0138, 0148, 0178, and 0211 (W. circinata) were identified as pathogenic to both common bean and maize. In the intergeneric tests, there were differences in disease severity in maize roots $(\mathrm{KW}=9.56 ; P=0.00839)$. Likewise, differences were found in root rot severity on common beans $(\mathrm{KW}=74.3 ; P<0.00001)$, with the highest average disease severity caused by $T$. cucumeris and Ceratobasidium spp. For the intrageneric analysis, there were significant differences for both plant species, with $\mathrm{KW}=154.9(P<$ $0.0001)$ for common bean and $\mathrm{KW}=112.0(P<0.0001)$ for maize (Fig. 3).

Phylogenetic analysis. The data phylogenetic analysis included 96 taxa, with the sequences trimmed to 781 base pairs. The MP analysis, including 207 parsimony-informative characters, produced a consensus tree (Fig. 4) that fit the genetic data $(\mathrm{RI}=0.888)$ with moderate level of nucleotide substitution $(\mathrm{CI}=0.584)$. In general, clustering occurred among isolates of the same AG and/or variety. However, some T. cucumeris and Ceratobasidium isolates shared the same clade, as well as T. cucumeris AG1 and AG4. W. circinata var. zeae isolates were divided into two clades and those labeled as W. circinata var. circinata did not cluster with their respective reference sequence. Most isolates from different geographical sites were spread throughout the cladogram. In some cases, a geographic

Table 2. Origin and identification of multinucleated Rhizoctonia species from the Brazilian Cerrado, as Waitea circinata anamorphs, according to nucleotide similarity analysis of the ITS1-5.8S-ITS2 regions

\begin{tabular}{|c|c|c|c|c|c|}
\hline Isolate ID & GenBank accession no. & Origin & Rhizoctonia species & Soil use & Recent cropping history \\
\hline CNPAF_0003 & KX468789 & Minas Gerais (MG) & zeae & Agricultural & No record \\
\hline CNPAF_0028 & KM065536 & MG & zeae & Agricultural & No record \\
\hline CNPAF_0038 & KX468791 & MG & circinata & Agricultural & Carrot \\
\hline CNPAF_0039 & KM065541 & MG & circinata & Agricultural & Soybean \\
\hline CNPAF_0042 & KM065544 & MG & circinata & Agricultural & Potato/Onion \\
\hline CNPAF_0043 & KM065545 & MG & circinata & Agricultural & Potato/Onion \\
\hline CNPAF_0045 & KM065548 & MG & circinata & Agricultural & Potato/Maize \\
\hline CNPAF_0046 & KX468793 & MG & circinata & Agricultural & Potato/Maize \\
\hline CNPAF_0047 & KX468794 & MG & circinata & Agricultural & Potato/Maize \\
\hline CNPAF_0056 & KM065553 & MG & zeae & Agricultural & Soybean \\
\hline CNPAF_0080 & KM065560 & MG & zeae & Agricultural & Coffee \\
\hline CNPAF_0095 & KM065562 & North (TO) & zeae & Agricultural & No record \\
\hline CNPAF_0102 & KX468798 & MG & zeae & Agricultural & Common bean \\
\hline CNPAF_0105 & KX468799 & MG & zeae & Agricultural & Common bean \\
\hline CNPAF_0108 & KX468800 & MG & circinata & Agricultural & Maize/Common bean \\
\hline CNPAF_0138 & KM065564 & Paraná (PR) & zeae & Agricultural & Maize/Common bean \\
\hline CNPAF_0141 & KM065565 & Goiás (GO) & circinata & Agricultural & No record \\
\hline CNPAF_0142 & KX468807 & PR & circinata & Agricultural & Cinnamon \\
\hline CNPAF_0143 & KM065566 & PR & circinata & Agricultural & Common bean/Sorghum \\
\hline CNPAF_0146 & KX468809 & PR & circinata & Agricultural & Common bean \\
\hline CNPAF_0148 & KX468810 & GO & zeae & Agricultural & Soybean \\
\hline CNPAF_0149 & KM065567 & GO & zeae & Agricultural & No record \\
\hline CNPAF_0154 & KX468812 & MG & zeae & Agricultural & No record \\
\hline CNPAF_0162 & KX468813 & GO & circinata & Agricultural & Common bean \\
\hline CNPAF_0178 & KX468814 & PR & zeae & Agricultural & Common bean/Oat \\
\hline CNPAF_0190 & KX468818 & PR & circinata & Agricultural & No record \\
\hline CNPAF_0191 & KX468819 & MG & zeae & Agricultural & Onion \\
\hline CNPAF_0211 & KM065569 & GO & oryzae & Agricultural & Rice \\
\hline CNPAF_0212 & KM065570 & GO & circinata & Agricultural & Rice \\
\hline CNPAF_0256 & KX468836 & MG & zeae & Agricultural & No record \\
\hline CNPAF_0274 & KX468841 & Bahia (BA) & zeae & Agricultural & No record \\
\hline CNPAF_0276 & KX468842 & BA & zeae & Agricultural & No record \\
\hline
\end{tabular}


structure was observed with some isolates grouping preferably by area, as for the Brazilian states of Roraima (RR), Mato Grosso (MT), Paraná (PR), and Minas Gerais (MG) (Fig. 4).

\section{Discussion}

Species, varieties, and AG identification. Morphological characteristics observed for the Waitea, Ceratobasidium, and Thanatephorus isolates were consistent with current descriptions for these three genera
(Kammerer et al. 2011; Sneh et al. 1991). Some inconsistencies were not resolved, however, even with the molecular results. Specifically, there was a conflict between the three isolates CNPAF_0036, CNPAF_0255, and CNPAF_0258. We identified these isolates as multinucleate Ceratobasidium species, contrary to their previous identification as binucleate, based on NCBI database. This mismatch is not unique with respect to the Rhizoctonia group and may be partly explained by the genetic similarity between Ceratobasidium and

Table 3. Origin and identification of multinucleated Rhizoctonia species from the Brazilian Cerrado, as Thanatephorus cucumeris anamorphs, according to nucleotide similarity analysis of the ITS1-5.8S-ITS2 regions

\begin{tabular}{|c|c|c|c|c|c|}
\hline Isolate ID & GenBank accession no. & Origin & Rhizoctonia solani $\mathbf{A G}^{\mathrm{a}}$ & Soil use & Recent cropping history \\
\hline CNPAF_0044 & KM065546 & Minas Gerais (MG) & AG4-HGIII & Agricultural & Carrot \\
\hline CNPAF_0053 & KM065550 & Goiás (GO) & AG4-HGIII & Agricultural & Soybean \\
\hline CNPAF_0054 & KM065551 & GO & AG4-HGIII & Agricultural & Soybean \\
\hline CNPAF_0055 & KM065552 & GO & AG4-HGIII & Agricultural & Soybean \\
\hline CNPAF_0061 & KM065555 & GO & AG1-1B & Agricultural & Soybean \\
\hline CNPAF_0062 & KM065556 & GO & AG4-HGI & Agricultural & Common bean \\
\hline CNPAF_0067 & KM065557 & MG & AG4-HGIII & Agricultural & Carrot \\
\hline CNPAF_0076 & KM065559 & MG & AG4-HGI & Agricultural & Soybean \\
\hline CNPAF_0081 & KX468795 & MG & AG1-1B & Agricultural & Coffee \\
\hline CNPAF_0082 & KX468796 & MG & AG1-1B & Agricultural & Coffee \\
\hline CNPAF_0119 & KX468802 & Paraná (PR) & AG4-HGI & Agricultural & Common bean \\
\hline CNPAF_0125 & KX468804 & PR & AG4-HGI & Agricultural & Common bean \\
\hline CNPAF_0144 & KX468808 & PR & AG4-HGI & Agricultural & Common bean \\
\hline CNPAF_0152 & KM065568 & $\mathrm{PR}$ & AG4-HGI & Agricultural & Common bean \\
\hline CNPAF_0180 & KX468815 & São Paulo (SP) & AG4-HGI & Agricultural & Common bean \\
\hline CNPAF_0193 & KX468820 & PR & AG4-HGI & Agricultural & Common bean \\
\hline CNPAF_0214 & KX468821 & Mato Grosso (MT) & AG1-1E & Agricultural & Common bean \\
\hline CNPAF_0215 & KX468822 & MT & AG1-1E & Agricultural & Common bean \\
\hline CNPAF_0224 & KX468823 & MT & AG1-1E & Agricultural & Common bean \\
\hline CNPAF_0236 & KX468824 & Roraima (RR) & AG1-1E & Native Vegetation & Forest \\
\hline CNPAF_0237 & KX468825 & $\mathrm{RR}$ & AG1-1E & Native Vegetation & Forest \\
\hline CNPAF_0238 & KX468826 & $\mathrm{RR}$ & AG1-1E & Native Vegetation & Forest \\
\hline CNPAF_0239 & KX468827 & $\mathrm{RR}$ & AG1-1E & Native Vegetation & Forest \\
\hline CNPAF_0240 & KX468828 & $\mathrm{RR}$ & AG1-1E & Native Vegetation & Forest \\
\hline CNPAF_0241 & KX468829 & $\mathrm{RR}$ & AG1-1D & Native Vegetation & Cerrado \\
\hline CNPAF_0242 & KX468830 & $\mathrm{RR}$ & AG1-1E & Native Vegetation & Cerrado \\
\hline CNPAF_0244 & KX468831 & $\mathrm{RR}$ & AG1-1E & Native Vegetation & Cerrado \\
\hline CNPAF_0246 & KX468832 & $\mathrm{RR}$ & AG1-1D & Native Vegetation & Cerrado \\
\hline CNPAF_0248 & KX468833 & $\mathrm{RR}$ & AG1-1E & Native Vegetation & Forest \\
\hline CNPAF_0249 & KX468834 & $\mathrm{RR}$ & AG1-1E & Native Vegetation & Forest \\
\hline
\end{tabular}

${ }^{\mathrm{a}}$ Anastomosis group.

Table 4. Origin and identification of Rhizoctonia species from the Brazilian Cerrado, as Ceratobasidium anamorphs, according to nucleotide similarity analysis of the ITS1-5.8S-ITS2 regions

\begin{tabular}{|c|c|c|c|c|c|}
\hline Isolate ID (nuclei number) & GenBank accession no. & Origin & Ceratobasidium $\mathbf{A G}^{\mathbf{a}}$ & Soil use & Recent cropping history \\
\hline CNPAF_0033 (binucleate) & KM065539 & Goias (GO) & AG-A & Agricultural & No record \\
\hline CNPAF_0036 (multinucleated) & KM065540 & GO & AG-Fa & Agricultural & Common bean \\
\hline CNPAF_0049 (binucleate) & KM065549 & Minas Gerais (MG) & AG-A & Agricultural & Coffee \\
\hline CNPAF_0058 (binucleate) & KM065554 & MG & AG-A & Agricultural & Carrot \\
\hline CNPAF_0088 (binucleate) & KX468797 & MG & AG-R & Agricultural & Onion \\
\hline CNPAF_0093 (binucleate) & KM065561 & Tocantins (TO) & $\mathrm{AG}-\mathrm{Fa}$ & Agricultural & Common bean \\
\hline CNPAF_0113 (binucleate) & KM065563 & MG & AG-G & Agricultural & Carrot \\
\hline CNPAF_0117 (binucleate) & KX468801 & Paraná (PR) & AG-A & Agricultural & Common bean \\
\hline CNPAF_0120 (binucleate) & KX468803 & PR & AG-A & Agricultural & Common bean \\
\hline CNPAF_0129 (binucleate) & KX468805 & PR & AG-A & Agricultural & Common bean \\
\hline CNPAF_0139 (binucleate) & KX468806 & PR & AG-F & Agricultural & Common bean \\
\hline CNPAF_0151 (binucleate) & KX468811 & PR & AG-F & Agricultural & Common bean \\
\hline CNPAF_0187 (binucleate) & KX468816 & PR & AG-A & Agricultural & Common bean \\
\hline CNPAF_0189 (binucleate) & KX468817 & $\mathrm{PR}$ & AG-F & Agricultural & Common bean \\
\hline CNPAF_0255 (multinucleated) & KX468835 & MG & AG-Fa & Agricultural & No record \\
\hline CNPAF_0258 (multinucleated) & KX468837 & MG & AG-P & Agricultural & No record \\
\hline CNPAF_0261 (binucleate) & KX468838 & MG & AG-F & Agricultural & No record \\
\hline CNPAF_0263 (binucleate) & KX468839 & MG & AG-P & Agricultural & No record \\
\hline CNPAF_0269 (binucleate) & KX468840 & Bahia (BA) & AG-F & Agricultural & No record \\
\hline
\end{tabular}

${ }^{a}$ Anastomosis group. 
Thanatephorus, whose evolutionary separation has not yet occurred entirely (González et al. 2001).

According to Lübeck (2004), the taxonomic position of some AGs within both genera is not clear. For instance, isolates from AG-6 (Thanatephorus) can merge hyphae with AG-F (Ceratobasidium). Phylogenetic analyzes also suggests that some isolates classified as Ceratobasidium based on a nuclei number and hyphae anastomosis could be assigned to Thanatephorus (González et al. 2001).

Disease severity evaluation for common bean and maize. Pathogenicity tests revealed the prevalence of phytopathogenic Rhizoctonias in the wide geographic area formed by the Brazilian Cerrado biome. These isolates differed in virulence when compared within the same AG or between different AGs, regarding the three teleomorphic genus found: T. cucumeris, W. circinata, and Ceratobasidium spp. These differences were attributed to the genetic variability of the isolates and specific traits of their respective AGs. Although common bean and maize are known hosts of both AG1-1B (Ceresini 2014) and AG1-1E (González et al. 2012), these isolates caused low to high root disease severity in common bean, and most of them were hypovirulent on maize roots. The hypovirulence of isolates on maize roots fits the lack of field records about Rhizoctonia species causing root rots on maize in Brazil. Therefore, their importance as root pathogens deserves further consideration.

Our findings identified 14 different taxa in the Cerrado soils that were pathogenic on common bean and maize, two of the most important crops grown for economic or subsistence purposes in Brazil. The cross-pathogenicity of some isolates on both hosts indicated the ability of Rhizoctonia spp. to survive in rotations with common bean and maize, a popular practice for many growers in the Cerrado.

Despite the differences in time during which the land was under cultivation, the main cropping sequence at the collection sites has been soybean (Glycine max), maize, and common bean. Though other hosts such as rice or vegetables may be locally relevant, specialized agriculture focused on one or few crops is a trend in all agricultural regions investigated and may favor the establishment of specialized forms of Rhizoctonia (Lakshman and Amaradasa 2014; Yang and Li 2012).

Distribution of Waitea circinata. W. circinata var. zeae was the most abundant variety among the 81 isolates and was identified in different agricultural regions across the sampling sites. Despite the popularity of maize production in all sampling regions, there are few reports of root rots in Brazil caused by the zeae variety of W. circinata (Poltronieri et al. 2002), and it is not clear if this pathogen is an underrated threat to maize in the country.

In contrast to the $W$. circinata varieties zeae and oryzae, W. circinata var. circinata was described recently, and is also related to diseases on the family Poaceae (Chen et al. 2009). Most of the $W$. circinata var. circinata isolates were found in the southeast region, mainly in Minas Gerais, and formed the second largest group of isolates within the Waitea genus. To our knowledge, this is the first report of the circinata variety in Brazil. On average, pathogenicity tests resulted in low disease severity on both common bean and maize; nevertheless, high levels of damage could occur on these hosts (Fig. 3).

Distribution of Ceratobasidium spp. Five Ceratobasidium AGs (AG-A, AG-F, AG-G, AG-R, and AG-P) identified here were previously related to areas where common bean has been cultivated (Mercado Cárdenas et al. 2015; Yang and Li 2012). Our results match the reports above, describing Ceratobasidium AGs in Paraná, Minas Gerais, Bahia, and Goiás. These states are important common bean producers, with a yield of nearly two million tons in 2014/2015 (MAPA 2015).

Distribution of Thanatephorus cucumeris. In areas of common bean cultivation, we found AG1-IE (Mato Grosso), AG4-HGI (Goiás, Paraná, and São Paulo), and AG4-HGIII (Goiás). AG4-HGI and AG4-HGIII were identified in soils under soybean production in Goiás and Minas Gerais, and AG1-1B was identified in soybean producing areas in Goiás and in coffee-growing areas in Minas Gerais (Table 3). AG1-IE and AG1-1B are causal agents of web blight on common bean and soybean, while AG4-HGI and AG4-HGIII of $R$. solani are well-known causes of root rots in on these crops (Ceresini 2014; González et al. 2012; Lakshman and Amaradasa 2014; MoraUmaña et al. 2013; Yang and Li 2012).

The identification of AG1 ISGs in non-agricultural soils in Roraima, northern Brazil, confirmed the existence of native Rhizoctonia species adapted to the equatorial environment. AG1 ISGs have been reported in the similar climates of Central America and the Caribbean islands (Godoy-Lutz et al. 2008; González et al. 2012; Mora-Umaña et al. 2013), mainly as economically important web blight pathogens of common bean (Godoy-Lutz et al. 1996, 2008). The presence of AG1 ISGs in native vegetation of northern Brazil is a potential risk to certain crops if this land is cleared for agriculture.
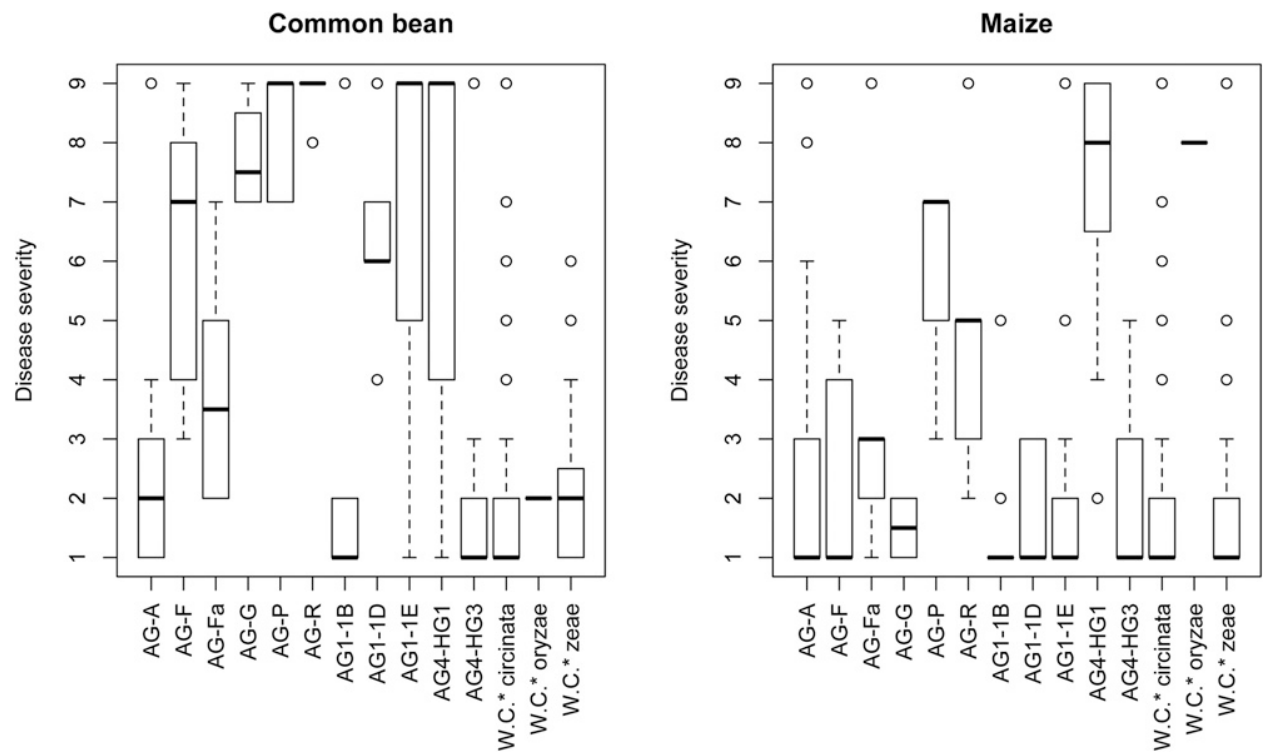

Fig 3. Mean root rot severity in maize and common bean caused by 14 different taxa of Rhizoctonia species isolates, identified as Ceratobasidium, Thanatephorus, and Waitea. Disease severity was assessed through the scale by Schoonhoven and Pastor-Corrales (1987), where $1=$ no visible symptoms; $3=$ from light discoloration and no necrotic lesions to a maximum of $10 \%$ of hypocotyl and root tissues with lesions; $5=$ approximately $25 \%$ of hypocotyl and root tissues have lesions, but the tissues remain firm; $7=$ approximately $50 \%$ of hypocotyl and root tissues have lesions, root systems with considerable decay and reductions; $9=$ approximately $75 \%$ or more of the hypocotyl and root tissues have lesions; roots with advanced stages of decay and considerable reduction. 
Phylogenetic-based clustering. Phylogenetic analysis showed that isolates belonging to the same variety or AG generally clustered based on geographic distance among the sampling sites (Tables 2, 3, 4, Fig. 4). This suggests an important correlation between genetic distance and geographic distance within the same variety or AG and a limited gene flow among the sampling sites.
Conversely, there may not be a complete evolutionary separation between some groups of isolates in the same AG that belong to different geographic regions but occupy the same clades (Fig. 4). The presence of some isolates outside the clades of their AGs or varieties linked to reference sequences may be explained by the high evolutionary rate and consequent amount of genetic variation in Rhizoctonia

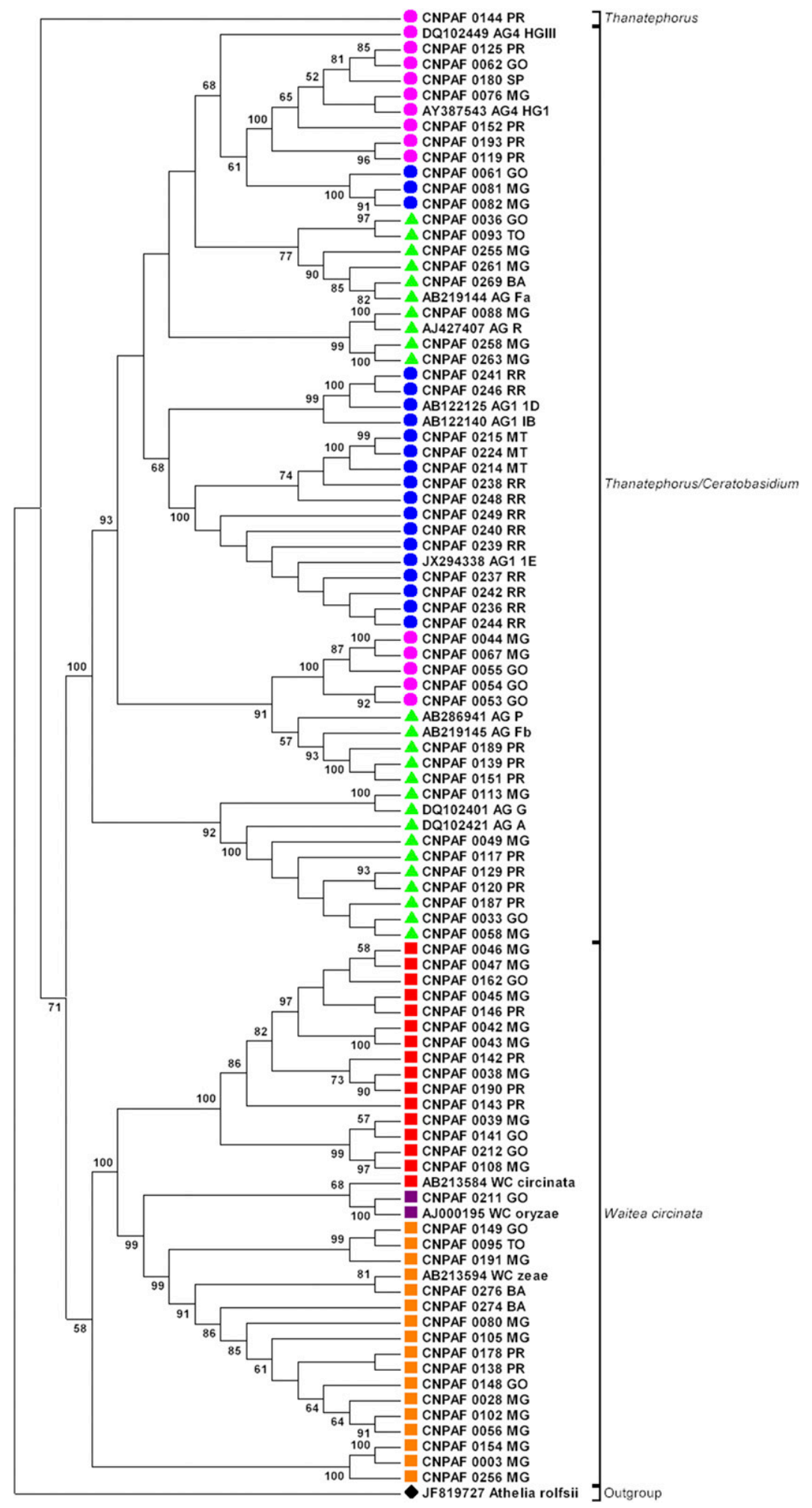

Fig. 4. Phylogenetic tree of 81 Brazilian Rhizoctonia isolates and 15 reference sequences, based on ribosomal ITS1-5.8S-ITS2 gene sequencing and maximum-parsimony criterion with 1,000 bootstraps. Only bootstraps above $50 \%$ are shown. Color and symbols show GenBank-NCBI identification. In blue: Thanatephorus cucumeris AG1; in pink: T. cucumeris AG4; in green: Ceratobasidium; in red: Waitea circinata var. circinata; in violet: W. circinata var. oryzae; in orange: W. circinata var. zeae. BA: Bahia; GO: Goiás; MT: Mato Grosso; MG: Minas Gerais; PR: Paraná; RR: Roraima; SP: São Paulo; TO: Tocantins. 
fungi. In T. cucumeris specifically, the alignment of the ITS-rDNA region can be difficult due to the excess number of insertions and deletions (Sharon et al. 2006). Isolates CNPAF 0061, CNPAF 0081, and CNPAF 0082, for example, were identified as AG1-IB (similarity $97 \%$, data not shown) and pooled together with the AG4-HGI isolates. Likewise, isolate CNPAF 144 was classified as AG4-HGI (similarity 99\%) and placed outside the clade containing all other isolates of this AG. The proximity between Thanatephorus and Ceratobasidium isolates (Fig. 4) occurs frequently in the literature (González et al. 2001; Mora-Umaña et al. 2013; Sharon et al. 2007, 2008).

The morphological differences among the Waitea, Ceratobasidium, and Thanatephorus colonies were not enough for species identification, but the molecular characterization of Rhizoctonia spp. also requires care to avoid mistakes during the sequence assignment to the NCBI database. Considering that our methodology included current, standard methods to estimate phylogenetic relationships within Rhizoctonia-related genera, our outcomes endorse previous reports for AG1 distribution typically in the equatorial zones (Godoy-Lutz et al. 2008; González et al. 2012; Mora-Umaña et al. 2013).

Our results suggest that the diversity of Rhizoctonia spp. in the Brazilian Cerrado resulted from the division of different species into varieties and AGs. Their geographic distribution varied between sampling sites, where three teleomorphic stages of the genus Rhizoctonia were classified, belonging to 14 different taxa. Gene flow between distant regions seemed to be limited. All isolates were pathogenic and caused root rot on common bean or maize, with $27.1 \%$ of the isolates infecting both host crops. These results reiterate the phytopathogenic importance of the Rhizoctonia species to Brazilian agriculture, especially on common bean. Further studies with larger, more representative samples of more specific areas may add new information relevant to disease management programs.

\section{Literature Cited}

Amaradasa, B. S., Lakshman, D. K., McCall, D., and Horvath, B. J. 2014. In vitro fungicide sensitivity of Rhizoctonia and Waitea isolates collected from turfgrasses. J. Environ. Hortic. 32:126-132.

Bandoni, R. J. 1979. Safranin O as a rapid nuclear stain for fungi. Mycologia 71: 873-874.

Bruehl, G. W. 1987. Soilborne plant pathogens. Macmillan Publishing Company, New York.

Carling, D. E., Kuninaga, S., and Brainard, K. A. 2002. Hyphal anastomosis reactions, rDNA-internal transcribed spacer sequences, and virulence levels among subsets of Rhizoctonia solani anastomosis group-2 (AG-2) and AGBI. Phytopathology 92:43-50.

Ceresini, P. C. 2014. Rhizoctonia como fitopatógeno: biologia e diversidade de Rhizoctonia solani em agroecosistemas tropicais e perspectivas do manejo da rhizoctoniose usando resistência de plantas. Pages 177-190 in: Sanidade de Raízes, 1st ed. NEFIT - Núcleo de Estudos em Fitopatologia, São Carlos, SP, Brazil.

Chaudhary, T. T., Anderson, T. T., Park, S. J., and Yu, K. 2006. Comparison of screening methods for resistance to Fusarium root rot in common beans (Phaseolus vulgaris L.). J. Phytopathol. 154:303-308.

Chen, C.-M., de la Cerda, K. A., Kaminski, J. E., Douhan, G. W., and Wong, F. P. 2009. Geographic distribution and rDNA-ITS region sequence diversity of Waitea circinata var. circinata isolated from annual bluegrass in the United States. Plant Dis. 93:906-911.

Ciampi, M. B., Gale, L. R., Lemos, E. G. de M., and Ceresini, P. C. 2009. Distinctively variable sequence-based nuclear DNA markers for multilocus phylogeography of the soybean-and rice-infecting fungal pathogen Rhizoctonia solani AG-1 IA. Genet. Mol. Biol. 32:840-846.

Costa-Coelho, G. R., Café Filho, A. C., and Lobo, M., Junior. 2014. A comparison of web blight epidemics on common bean cultivars with different growth habits. Crop Prot. 55:16-20.

Costa-Coelho, G. R., Toledo-Souza, E. D., Café-Filho, A. C., and Lobo, M., Junior. 2016. Dynamics of common bean web blight epidemics and grain yields in different tillage systems. Trop. Plant Pathol. 41:306-311.

de la Cerda, K., Douhan, G., and Wong, F. 2007. Discovery and characterization of Waitea circinata var. circinata affecting annual bluegrass from the Western United States. Plant Dis. 91:791-797.

Fenille, R. C., Souza, N. L., and Kuramae, E. E. 2002. Characterization of Rhizoctonia solani associated with soybean in Brazil. Eur. J. Plant Pathol. 108:783-792.

Gaino, A. P. S. C., Basseto, M. A., Gasparotto, L., Poltronieri, L. S., and Ceresini, P. C. 2010. Inferência filogenética revela a complexa etiologia das manchas areolada e foliar em seringueira e em outras espécies cultivadas na Amazônia. Acta Sci. Agron. 32:385-395.

Godoy-Lutz, G., Arias, J., Steadman, J. R., and Eskridge, K. M. 1996. Role of natural seed infection by the web blight pathogen in common bean seed damage, seedling emergence, and early disease development. Plant Dis. 80: 887-890.

Godoy-Lutz, G., Kuninaga, S., Steadman, J. R., and Powers, K. 2008 Phylogenetic analysis of Rhizoctonia solani subgroups associated with web blight symptoms on common bean based on ITS-5.8S rDNA. J. Gen. Plant Pathol. 74:32-40.

González, M. D., Carling, D. E., Kuninaga, S., Vilgalys, R., and Cubeta, M. A. 2001. Ribosomal DNA systematics of Ceratobasidium and Thanatephorus with Rhizoctonia anamorphs. Mycologia 93:1138-1150.

González, M. D., Cubeta, M. A., and Vilgalys, R. 2006. Phylogenetic utility of indels within ribosomal DNA and beta-tubulin sequences from fungi in the Rhizoctonia solani species complex. Mol. Phylogenet. Evol. 40:459-470.

González, N., Godoy-Lutz, G., Steadman, J. R., Higgins, R., and Eskridge, K. M. 2012. Assessing genetic diversity in the web blight pathogen Thanatephorus cucumeris (anamorph = Rhizoctonia solani) subgroups AG 1-IE and AG 1-IF with molecular markers. J. Gen. Plant Pathol. 78:85-98.

González-García, V., Portal-Onco, M. A., and Rubio-Susan, V. 2006. Review: Biology and Systematics of the form genus Rhizoctonia. Span. J. Agric. Res. 4:55-79.

Hall, T. A. 1999. BioEdit: a user-friendly biological sequence alignment editor and analysis program for Windows 95/98/NT. Nucleic Acids Symp. Ser. 41:95-98.

Hua, G. K. H., Bertier, L., Soltaninejad, S., and Höfte, M. 2014. Cropping systems and cultural practices determine the Rhizoctonia anastomosis groups associated with Brassica spp. in Vietnam. PLoS One 9:e111750.

Johanson, A., Turner, H. C., McKay, G. J., and Brown, A. E. 1998. A PCR-based method to distinguish fungi of the rice sheath-blight complex, Rhizoctonia solani, R. oryzae and R. oryzae-sativae. Microbiol. Lett. 162:289-294.

Kammerer, S. J., Burpee, L. L., and Harmon, P. F. 2011. Identification of a new Waitea circinata variety causing basal leaf blight of Seashore paspalum. Plant Dis. 95:515-522.

Lakshman, D. K., and Amaradasa, B. S. 2014. The pathogen biology, identification and management of Rhizoctonia species with emphasis on isolates infecting turfgrasses. Indian Phytopathol. 67:327-345.

Leiner, R. H., and Carling, D. E. 1994. Characterization of Waitea circinata (Rhizoctonia) isolated from agricultural soils in Alaska. Plant Dis. 78:385-388.

Li, H. R., Wu, B. C., and Yan, S. Q. 1998. Aetiology of Rhizoctonia in sheath blight of maize in Sichuan. Plant Pathol. 47:16-21.

Lopes, F. A. C., Steindorff, A. S., Geraldine, A. M., Brandão, R. S., Monteiro, V. N., Lobo-Junior, M., Coelho, A. S. G., Ulhoa, C. J., and Silva, R. N. 2012. Biochemical and metabolic profiles of Trichoderma strains isolated from common bean crops in the Brazilian Cerrado, and potential antagonism against Sclerotinia sclerotiorum. Fungal Biol. 116:815-824.

Lübeck, M. 2004. Molecular characterization of Rhizoctonia solani. Pages 205-224 in: Applied Mycology \& Biotechnology, vol. 4: Fungal Genomics. Pergamon Press, Oxford, U.K.

MAPA. 2015. Projeções do agronegócio: Brasil 2014/15 a 2024/25: projeções de longo prazo. 6. ed. Ministério da Agricultura, Pecuária e Abastecimento (MAPA), Brasília, Brazil. http://www.brasilagro.com.br/imagens/projecoes_do_agronegocio_ 2025_web-ok.pdf

Mercado Cárdenas, G. E. M., Galvan, M. Z., Barrera, V. A., Rodriguero, M. S., Carmona, M. A., March, G. J., Ramallo, A. C., and Shew, H. D. 2015 Molecular identification and pathogenicity of Rhizoctonia spp. from tobacco growing areas in northwestern Argentina. Trop. Plant Pathol. 40:160-168.

Mora-Umaña, F., Barboza, N., Alvarado, R., Vásquez, M., Godoy-Lutz, G., Steadman, J. R., and Ramírez, P. 2013. Virulence and molecular characterization of Costa Rican isolates of Rhizoctonia solani from common bean. Trop. Plant Pathol. 38:461-471.

Nechet, K. L., and Halfeld-Vieira, B. A. 2006. Caracterização de isolados de Rhizoctonia spp., associados à mela do feijão caupi (Vigna unguiculata), coletados em Roraima. Fitopatol. Bras. 31:505-508.

Ogoshi, A. 1987. Ecology and pathogenicity of anastomosis and intraspecific groups of Rhizoctonia solani Kühn. Annu. Rev. Phytopathol. 25:125-143.

Paulitz, T. C., and Schroeder, K. L. 2005. A new method for the quantification of Rhizoctonia solani and R. oryzae from Soil. Plant Dis. 89:767-772.

Poltronieri, L. S., Trindade, D. R., and Albuquerque, F. C. 2002. Rhizoctonia zeae causando podridão em milho no estado do Pará. Fitopatol. Bras. 27:423.

R Core Team. 2015. R: A language and environment for statistical computing. R Foundation for StatisticalComputing, Vienna, Austria. https://www.R-project. org/

Schoonhoven, A. V., and Pastor-Corrales, M. A. 1987. Standard system for the evaluation of bean germplasm. CIAT - Centro Internacional de Agricultura Tropical, Cali, Colombia.

Sharon, M., Freeman, S., Kuninaga, S., and Sneh, B. 2007. Genetic diversity, anastomosis groups and virulence of Rhizoctonia spp. from strawberry. Eur. J. Plant Pathol. 117:247-265.

Sharon, M., Sneh, B., Kuninaga, S., and Hyakumachi, M. 2006. The advancing identification and classification of Rhizoctonia spp. using molecular and biotechnological methods compared with the classical anastomosis grouping. Mycoscience 47:299-316.

Sharon, M., Sneh, B., Kuninaga, S., Hyakumachi, M., and Naito, S. 2008 Classification of Rhizoctonia spp. using rDNA-ITS sequence analysis supports the genetic basis of the classical anastomosis grouping. Mycoscience 49:93-114.

Sneh, B., Burpee, L., and Ogoshi, A. 1991. Identification of Rhizoctonia species. APS Press, St. Paul, MN. 
Sneh, B., Jajabi-Hare, S., Neate, S., and Dijst, G., eds. 1996. Rhizoctonia species: taxonomy, molecular biology, ecology, pathology and disease control. Kluwer Academic Publishers, Boston.

StatSoft, Inc. 2007. STATISTICA (Data Analysis Software System), Version 8. http://statistica.io

Tamura, K., Stecher, G., Peterson, D., Filipski, A., and Kumar, S. 2013. MEGA6: Molecular evolutionary genetics analysis version 6.0. Mol. Biol. Evol. 30: 2725-2729.

Toda, T., Hyakawa, T., Mwafaida Mghalu, J., Yaguchi, S., and Hyakumachi, M. 2007. A new Rhizoctonia sp. closely related to Waitea circinata causes a new disease of creeping bentgrass. J. Gen. Plant Pathol. 73:379-387.

Toda, T., Mghalu, J., Pryatomojo, A., and Hyakumachi, M. 2004. Comparison of sequences for the internal transcribed spacer region in Rhizoctonia solani AG 1-ID and other subgroups of AG 1. J. Gen. Plant Pathol. 70: 270-272.

Weinhold, A. R. 1977. Population of Rhizoctonia solani in agricultural soils determined by a screening procedure. Phytopathology 67:566-569.

White, T. J., Bruns, T. D., Lee, S. B., and Taylor, J. W. 1990. Amplification and direct sequencing of fungal ribosomal RNA genes for phylogenetics. Pages 315-322 in: PCR Protocols: A Guide to Methods and Applications. M. A. Innis, D. H. Gelfand, J. J. Sninsky, and T. J. White, eds. Academic Press, San Diego, CA.

Yang, G., and Li, C. 2012. General description of Rhizoctonia species complex. Pages 41-52 in: Plant Pathology. C. J. Cumagun, ed. InTech, Rijeka, Croatia. https://www.intechopen.com/books/plant-pathology/general-description-ofrhizocotonia-species-complex 